\title{
Mechanical and biotic strategies for post-mine reclaimed grasslands
}

\author{
Maureen Puffer ${ }^{1}$, Ryan Limb ${ }^{1}$, Aaron Daigh ${ }^{1}$, and Kevin Sedivec ${ }^{1}$ \\ ${ }^{1}$ North Dakota State University
}

February 20, 2022

\begin{abstract}
Global energy production is in high demand and is expanding its development into new landscapes, including grasslands. This expansion has intensive impacts on above and belowground components of grasslands which need to be addressed during reclamation to promote long-term ecological integrity. This study was conducted to ascertain how alternative reclamation practices may improve soil structure (i.e., compaction) while aiding in the creation of conditions that are conducive for both the establishment and continued growth of native grassland plant species. The grassland was reclaimed with different combinations of seeding mixtures (grass or grass and forb), ripping techniques (subsoil ripping or topsoil ripping), and the integration of mulch into the soil profile. Species composition and abundance of the vegetation community was estimated, and volumetric soil moisture and penetration resistance readings were obtained. Year, seed mixtures, ripping techniques and their interactions significantly affected community composition and species diversity. Topsoil-ripping and grass-forb treatment had a higher association with native, perennial grasses while subsoil-ripping and grass treatment favor more short-lived species. Similar trends persisted across penetration resistance and soil moisture readings where topsoil-ripping and grass-forb treatment were different from subsoil-ripping and Grass treatments $(\mathrm{p}<0.10)$. Additionally, Kentucky bluegrass, an invasive grass species, increased $76 \%$ over one year and was more common in the topsoil-ripping and grass-forb treatments. While early in the reclamation process, results suggest topsoil-ripping and grass-forb treatment are a promising combination reclamation practice that can establish a native grassland community and initiate the improvement of compacted soil conditions.
\end{abstract}

Title: Mechanical and biotic strategies for post-mine reclaimed grasslands

Running head: Post-mine reclamation

Authors and addresses: Maureen Puffer ${ }^{1}$, Ryan F. Limb ${ }^{2}$, Aaron L.M. Daigh ${ }^{2}$ and K.K. Sedivec ${ }^{3}$

Authors are: ${ }^{1}$ Graduate Research Assistant, School of Natural Resource Sciences, North Dakota State University, Fargo, ND 58102, USA $;^{2}$ Associate Professor, School of Natural Resource Sciences, North Dakota State University, Fargo, ND 58102, USA; ${ }^{3}$ Professor School of Natural Resource Sciences, North Dakota State University, Fargo, ND 58102, USA

Correspondence: Ryan F. Limb 201C Morrill Hall, NDSU Bolley Drive, Fargo, ND 58102

Email:ryan.limb@ndsu.edu, P:701.231.5828, F:701.231.8557

\section{Key words:}

reclamation, soil ripping, soil compaction, plant composition, invasive species

\section{Introduction}

Global energy production and activities preceding production are expected to expand into new landscapes in response to the increased demand for energy (McDonald et al. 2009). Numerous negative consequences are associated with such activities including fragmentation (Trainor et al. 2016), habitat loss (Shaffer \& Buhl 2016), alterations to soil structure (Stumpf et al. 2016), and the loss of productive landscapes (Allred et 
al. 2015). However, in many cases (i.e., surface mining) reclamation is required post-extraction to promote a return of productivity to the landscape (SMCRA 1977). Among the many ecosystems affected by the development of energy-based infrastructure are the grasslands of the Northern Great Plains (NGP) (Preston \& Kim 2016), which is where multiple forms of non-renewable resources are being extracted, including lignite coal. Current traditional best reclamation practices on lignite coalmines result in reclaimed lands being successfully released from performance bonds after 10 years. Yet, ensuring soil structural recovery and sustaining a diverse plant community on reclaimed grasslands remains a challenge, especially as time since reclamation progresses (Bohrer et al. 2017a; Bohrer et al. 2017b).

Surface mining activities require large-scale excavation of earthen materials resulting in the complete deconstruction of ecosystems (Holl 2002; Pauletto et al. 2016). Excavation of all existing vegetation and deconstruction of soil profiles is among the first stages of surface mining. Such activities results in extreme alterations to soil structure, specifically larger soil aggregates ( Stumpf et al. 2016). Soil aggregates are further degraded by the vibrations during the course of transportation (McSweeney \& Jansen 1984). These cumulative impacts on soil aggregates become problematic during reclamation as heavy load-bearing pressures from reclamation equipment (responsible for stabilizing and grading the newly constructed landscape) compress the degraded soil aggregates (McSweeney \& Jansen 1984; Bohrer et al. 2017b). Compression of these altered aggregates creates compacted soil conditions, and such conditions have the potential to cause many obstacles when attempting to establish and sustain a desired plant community.

Connectivity of macropores within the soil matrix is essential for water infiltration, promotion nutrient of cycling, and providing plant roots accessibility to resources like nutrients, water, oxygen, and heat ( Stoessel et al., 2018). Soil compaction increases bulk density and penetration resistance (PR), reducing the distribution of macropores in the soil profile (Jabro et al. 2014), affecting growth of plant roots (Tardieu 1994; Unger \& Kaspar 1994), the accessibility of water to plant roots (Haygarth \& Ritz, 2009), and the overall movement of water (Kulli et al. 2003). Plants must exert more energy to obtain water and nutrients, and if water cannot be obtained the plants become stressed. Additionally, limited infiltration and pooling may also occur at either the surface or subsurface, which impacts the availability of water and/or oxygen to plant roots (Hamza \& Anderson 2004; Stoessel et al. 2018) and increase the likelihood of soil erosion (Stoessel et al. 2018). Decreased macropores can also impede the ability of plant roots to maneuver within the soil profile and altering the growth patterns (Hernandez-Ramirez et al. 2014; Beckett et al. 2017). Finding a solution to improve root growth and water movement becomes vital during the reclamation process.

Alleviating soil compaction can be accomplished using a variety of anthropogenic methods, including mechanized disruption of soil or amending the soil with organic matter (Hamza \& Anderson 2004). Tilling is one of the most common land management practices used to decrease soil compaction (Schneider et al. 2017). This technique breaks up the compressed layer of soil and increases the amount and distribution of macropores (Hangen et al. 2002). Tilling-like practices applied to reach subsoil depths is often referred to as ripping, or subsoiling (Schneider et al. 2017). An additional means of decreasing compaction is the integration of organic matter (OM), e.g. material such as straw, into the soil (Getahun et al. 2018). This management practice can aid in alleviating compaction in two ways. The capabilities of OM to absorb water improves the soil water-holding capacity enhancing the availability of water to plant roots (Zhao et al. 2014). Also, as organic materials decompose they aid in soil aggregation by adding organic carbon (Sheoran 2010). The application of these practices improves the pore space distribution which in turn promotes water movement, root exploration, and decreases the bulk density and penetration resistance. Ultimately, these actions have the potential to improve growing conditions and the establishment of desirable native grassland species. However, these conditions may also promote invasive species like Kentucky bluegrass (Poa pratensis ), a cool season invasive grass of special concern in the NGP.

Grasslands in the NGP are being disturbed to support energy production-based infrastructure (Preston \& Kim 2016), but mandatory reclamation for surface-mining operations provides an opportunity for native grasslands to be replaced by new reconstructed grasslands. Unfortunately, conditions of older reclaimed grasslands, both above and belowground, are not presenting ecological qualities representative of functional 
grasslands (Bohrer et al. 2017a; Bohrer et al. 2017b), prompting a need to investigate alternative reclamation practices. The objective of this study was to compare how different combinations of alternative reclamation practices can influence community composition, reduce PR, and improve soil water movement. We expect to observe quantifiable differences between the different combinations when assessing the plant community composition, PR, and volumetric soil moisture.

\section{Methods}

This study took place on BNI Mine Ltd property, located approximately $6 \mathrm{~km}$ SE of Center, ND (lat. 47 $02^{\prime}$ $52.66^{\prime \prime} \mathrm{N}$ long. $\left.101^{\circ} 14^{\prime} 31.61^{\prime \prime} \mathrm{W}\right)$. This project site falls within the Northern Great Plains ecoregion with temperatures ranging between $-11^{\circ} \mathrm{C}$ and $22^{\circ} \mathrm{C}$ (NDAWN 2020), and an average of 150 frost-free days per year. Average growing season precipitation is $355 \mathrm{~mm}$ (NDAWN 2021). Soils consisted of silt loams, loams, and silty clay loams complexes prior to mining; however, they are then reclassified as "mined-land complex" (USDA-NRCS 2021a) post-mining.

The project site was stripped mined between 2015 and 2016, and subsequent reclamation completed by April/May of 2018. Installation of our research plots occurred during reclamation and comprised of the following factors: two seeding mixtures, deep ripping at one of two phases of reclamation, and incorporation of mulch into the subsoil horizon. All combinations of factors are represented at the designated location.

Half of the treatments were planted to a grass only seed mixture $(\mathrm{G})$ and the other half seeded to a grass and forb seed mixture (G/F) (Table 1). Deep ripping occurred either within the subsoil horizon prior to topsoil replacement (SSR) or across both the subsoil and topsoil horizons after topsoil replacement (TSR). Ripping shanks reached maximum depths of $56 \mathrm{~cm}$. Straw mulch was applied to the subsoil surface at 1130-1360 $\mathrm{kg} / \mathrm{ha}$ and then incorporated into the surface of the soil via disking. The reference site was seeded with the grass/forb mix and proceeded with standard reclamation practices which did not include ripping or mulch. Each combination was replicated twice and the reference site once, and each unit was approximately 0.6 hectares.

Plant community composition and canopy cover surveys were conducted by randomly establishing three 60 meter transects in each treatment unit. We placed a $0.5 \mathrm{~m}^{2}$ frame every 15 -meters along each transect and identified every plant to a species level. We measured abundance by estimated canopy cover of each species and assigned one of the following modified Daubenmire cover classes, $1=$ trace $-1 \%, 2=1-2 \%, 3=2-5 \%, 4=$ $5-10 \%, 5=10-20 \%, 6=20-30 \% \ldots 13=90-95 \%, 14=95-98 \%, 15=98-99 \%$, and $16=99-100 \%$ (Daubenmire, 1959).

Surveys were conducted in 2019 and 2020 during peak production (mid-July) and mid-point values were used for analysis. We referenced the USDA Plant Database (USDA-NRCS 2021b) to classify each species' seasonality, metabolic pathway, and origin (native versus exotic) after completion of surveys.

We installed three soil moisture access tubes into the soil profile of each treatment unit. Tubes were a minimum of 30-meters in from the plot's edges, a minimum of five-meters from other units and installed to a depth of one meter. A soil moisture probe was used to take three separate readings at 10, 20, 30, 40, 60 , and $100 \mathrm{~cm}$ intervals (Delta-T Device Ltd, UK). We rotated the probe $120^{\circ}$ before the second and third readings to account for any soil moisture variability within the soil profile. Our analysis used averages from each tube.

Four penetration resistance readings were taken to a depth of one meter with an automated dynamic cone penetrometer (ADCP; Vertek, USA). We obtained each reading by positioning the ADCP approximately three meters away from the associated access tubes in each of the cardinal directions. Readings automatically recorded were later converted to joules per meter. The method for calculating penetration resistance is based on the soil's capacity to cease work being performed by the penetrometer divided by how far the penetrometer progressed:

$R_{s}=\frac{W_{s}}{P_{d}}(1)$ 
Where: $R_{\mathrm{s}}$ is the soil resistance $(\mathrm{N}), \mathrm{W}_{\mathrm{s}}$ is the kinetic energy of the $(\mathrm{J})$, and $\mathrm{P}_{\mathrm{d}}$ is the depth traveled by the penetrometer through the soil (Equation 1).

We used averaged species cover values calculated from all frames within a transect across each treatment replication. Generalized linear models were used to test the effects of seeding method, ripping technique, and mulching and their interactions on species richness, diversity, and KBG cover. Tukey post-hoc tests followed any significant ANOVA results $(\mathrm{p}<0.10)$. We performed a separate analysis for each year of data for models of species richness, diversity and KBG cover. We ran nonmetric dimensional scaling analyses (NMDS) and permutational multivariate analysis of variance (PERMANOVA) for 2019 and 2020 separately to understand dissimilarities in species composition between each treatment (Oksanen et al. 2019). Ordinations were calculated in three dimensions using Bray-Curtis distance measures. To further assess the differences in community composition we added plant functional trait data as vectors using envfit. We performed all our analyses using $\mathrm{R}$ version 4.0.4 (R Development Core Team 2021) and the following packages car (Fox \& Weisberg 2019), agricolea (Mendiburu 2020), vegan (Oksanen et al. 2019).

We used linear mixed effect models to analyze each of the soil moisture depth intervals. We included treatment as the fixed effect and year, replication, and observation point random effects. Tukey's post- hoc tests were performed for those soil moisture depth intervals that returned significant differences between treatments $(\mathrm{p}<0.10)$. We used lme4 (Bates et al. 2015) for our linear mixed effect model and lsmeans (Lenth 2016) for our post- hoc tests. These same packages were used in the following section as well.

We selected three separate depth bins of 0-15, 15-30, and 30-100 cm after a preliminary analysis determined no significant differences for depth intervals falling between 30 and $100 \mathrm{~cm}$. We averaged the four ADCP readings at each observation point to simplify our model random effects structure. We found no interaction between treatment and depth allowing treatment to be a fixed effect in our linear mixed effect model. Volumetric soil moisture readings were included as a covariate to our models to account for the variability of soil moisture at different depths which may influence PR values. We used the 10, 20, and $60 \mathrm{~cm}$ soil moisture depth interval averages for the 0-15, 15-30, and 30-100 cm depth bins, respectively. Readings from the ADCP took place in the same location over the course of three years. Therefore, we included year, replication, and observation point (i.e., location associated with the access tube) as nested random effects in our model. We ran this linear mixed effect model separately for all three depths. We performed subsequent Tukey's post-hoc procedures with $90 \%$ confidence intervals when the model returned significant differences between treatments $(\mathrm{p}<0.10)$.

\section{Results}

Our surveys resulted in the identification of 52 and 57 species in 2019 and 2020, respectively. Seven grass species and five forb species present in the seed mix were found in both 2019 and 2020. Both ripping, seeding mixture, and a ripping/seeding interaction showed a significant effect on species richness in 2019 $(\mathrm{p}<0.10)$ (Figure 1). Species richness ranged between an average of 18 and 9 species in 2019, and 16 and 9 species in 2020. However, only seeding mixture influenced species richness in $2020(\mathrm{p}<0.10)$ (Figure 2). Treatments planted to G/F had significantly more species in both years, while treatments reclaimed with TSR had significantly more species only in 2019. Simpson diversity showed a wider range of values between treatments in 2019 compared to 2020 with values ranging from 0.75-0.47 and 0.84-0.75, respectively (Figure 3 and 4). Trends show that treatments reclaimed with TSR and treatments planted with G/F have the largest average diversity values in 2019 and 2020, respectively. Mulch did not have any significant impact on either species richness or diversity.

Year $(\mathrm{p}=0.001)$ (Figure 5) and two of the main effects, seeding $(\mathrm{p}=0.002)$ and ripping $(\mathrm{p}=0.006)$, impacted plant community composition, when both years were assessed collectively. Additionally, year and seeding $(\mathrm{p}=0.037)$ and ripping and seeding $(\mathrm{p}=0.022)$ interactions influenced species composition and abundance. Consequently, subsequent analyses were separated by year to evaluate how the main effects impacted the plant community. We used functional groups to explain primary drivers of plant composition.

Both seeding and ripping, and a seeding/ripping ( $\mathrm{p}=0.056)$ interaction had a significant effect on the plant 
community composition in $2019(\mathrm{p}<0.10)$ (Figure 6). The primary functional groups driving the 2019 plant community composition were native, perennial, C3 grasses on NMDS axis 1, short-lived perennials on NMDS axis 2, and annual/biennials and C3 forbs on NMDS axis $3(\mathrm{p}<0.10)$ (Table 2). Additionally, percent volumetric soil moisture at 30 and $40 \mathrm{~cm}$ depth ranges, around the topsoil/subsoil interface were primary drivers of plant composition on the NMDS 2 and NMDS 1, respectively (Table 2).

Seeding and ripping were significant main effects in $2020(\mathrm{p}<0.10)$, and additional analysis revealed a significant seeding/ripping interaction $(\mathrm{p}=0.016)$ (Figure 7). Species composition in 2020 was primarily driven by $\mathrm{C} 4$ species, and annuals on NMDS axis 1, long and short-lived perennials and native species on NMDS axis 2, and all C3 species on NMDS axis $3(\mathrm{p}<0.10)$ (Table 2). Both 30 and $40 \mathrm{~cm}$ depth ranges for percent volumetric soil moisture were also a primary drivers of species composition on NMDS axis 2 (Table 2).

Year influenced Kentucky bluegrass abundance $(\mathrm{p}=0.029)$ with percent cover increasing by $76 \%$ between 2019 and 2020 (Figure 8). Seeding mixture $(\mathrm{p}=0.017)$ and ripping $(\mathrm{p}=0.004)$ influenced the abundance of KBG when both years were assessed collectively (Figure 7 ). Treatments planted with $G$ and reclaimed with SSR (plus mulch) had significantly less KBG compared to the site planted to G/F and reclaimed with TSR (Figure 8).

Early trends indicate that treatments reclaimed with SSR and planted with G (plus mulch) have the highest PR values with means of 35.9 (37.1), 44.9 (50.2), and 45.7 (48.7) J/m; respective, to treatment(s) and depths. Furthermore, those treatments planted with G/F and reclaimed with TSR consistently have the lowest PR values with means of $25.6,28.1$, and $33.2 \mathrm{~J} / \mathrm{m}$; respective by depth. The treatments with the highest mean PR readings are significantly different than treatments with lowest mean PR readings, at all three depths ( $\mathrm{p}<$ 0.10) (Figure 9). G, SSR, plus mulch treatments at the 15-30 cm depth bin were statistically different from all other treatments other than the G and SSR treatment. Additional differences between treatments exist at depths of 15-30 and 30-100, but differences in means appear to be between those with the same seeding mixture or the same ripping technique. There was no indication that standard reclamation procedures (i.e., the control) resulted in significantly different penetration resistance readings at any depth, at this time (Figure 9).

Treatments planted with G, SSR, plus mulch were significantly different to treatments planted with G, TSR, plus mulch and treatments planted with G/F and TSR $(\mathrm{p}<0.10)$, at the 20,30, and 40 depth intervals. Additionally, trends reveal there are significant differences between treatments with the same seed mixtures and/or ripping techniques at both 30 and $40 \mathrm{~cm}$ depth intervals. Treatments planted with $\mathrm{G} / \mathrm{F}$ and reclaimed with TSR (plus mulch) were most frequently different to those treatments across both seeding mixtures and ripping techniques (Figure 9).

Standard reclamation procedures (i.e., reference site) had significantly greater $(\mathrm{p}<0.10)$ volumetric soil moisture at the $40 \mathrm{~cm}$ depth than those treatments planted with $\mathrm{G} / \mathrm{F}$ and reclaimed with TSR. Volumetric soil moisture readings at the 10 and $60 \mathrm{~cm}$ depths showed no differences between treatments $(\mathrm{p}>0.10)$ (Figure 10). We did not assess the $100 \mathrm{~cm}$ depth interval because it likely has no influence over plant community dynamics this early in the reclamation phase. At the 20,30, and 40 depth intervals mean percent values of those treatments planted with G, SSR, plus mulch $(22.3,23.7,26.0$, respective of depth) had significantly greater volumetric soil moisture compared to treatments planted with G, TSR, plus mulch $(16.7,18.8,19.4$, respective of depth) and treatments planted with G/F and TSR (17.2, 17.9, 15.7, respective of depth). The number of treatments showing significant differences increased with depth with the greatest variability being observed at both the 30 and $40 \mathrm{~cm}$ depth intervals. Significant differences between combinations exist between treatments with the same ripping techniques and same seeding mixture $(\mathrm{p}<0.10)$ (Figure 10). Treatments planted with G/F and reclaimed with TSR (plus mulch) were most frequently different to those treatments across both seeding mixtures and ripping techniques (Figure 10). Standard reclamation procedures (i.e., the reference site) had significantly greater volumetric soil moisture at the $40 \mathrm{~cm}$ depth than those treatments planted with $\mathrm{G} / \mathrm{F}$ and reclaimed with TSR $(\mathrm{p}<0.10)$. Volumetric soil moisture readings at the 10 and 60 $\mathrm{cm}$ depths showed no differences between treatments ( $\mathrm{p}>0.10)$ (Figure 10). 


\section{Discussion}

Pre-extraction processes of surface mining and subsequent reclamation activities provide efficient means of de-constructing and re-constructing a new landscape. However, belowground conditions resulting from these current best management practices (i.e., compacted soils) produce challenging circumstances for establishing and sustaining a new diverse plant community (Bohrer et al. 2017a). Furthermore, the presence and establishment of exotic species, like KBG, add additional stresses to fostering a desirable plant community (Bohrer et al. 2017b). In an attempt to address these various challenges associated with a reclaimed landscape, we explored the impacts of alternative reclamation practices on a newly reclaimed grassland. We found that plant composition significantly differed between 2019 and 2020, and two out of three of the treatment effects (i.e., seed mix and ripping) had a significant effect on the plant community composition, regardless of year. Additionally, penetration resistance and soil moisture readings are showing early trends that suggests a distinction between treatments.

Distinct plant community assemblages are beginning to form in response to seeding mixtures, ripping techniques, and their interaction over time. TSR and G/F treatments frequently shared plant community primary drivers across all functional groups, in 2019. These treatments were commonly associated with native perennials, C3 grasses, and C3 forbs. This trend is likely attributed in large part to the seed mix, but also the improved growing conditions for vegetation provided by ripping from the topsoil horizon (Ashby 1997; Bauman et al. 2014; Fields-Johnson et al. 2014). C3 grasses occurred more often with G/F and TSR treatments, yet planted C3 grass species (i.e., NAVI (Nassella viridula) and PASM (Pascopyrum smithii)) were commonly found on all treatments in both years. The USDA Natural Resources Conservation Service recommended these native species for revegetating disturbed/reclaimed landscapes which likely contributes to their high proportion use in the seed mix and them being well represented.

Generally, shorter-lived species (i.e., annuals and short-lived perennials) occurred in G and SSR treatments in 2019. This representation of short-lived species is typical of recently disturbed/reclaimed landscapes (Foster \& Tilman 2000; Alday et al. 2011) and may explain some of the increases of species richness found among $\mathrm{G}$ and SSR treatments experienced from 2019 to 2020. However, some of the G/F and TSR treatments also experienced increases in species richness between 2019 and 2020 without a heavy association with short-lived species. Fluctuation of species richness in the early stages of ecological recovery is a commonly documented occurrence in previous grassland restoration work (Sluis 2002; Middleton et al. 2010). Changes in species richness between 2019 and 2020 suggests that all treatments, but especially G and SSR treatments, may experience more pronounced shifts in species composition over time.

By the second sampling season interactions between TSR and G/F treatments and G and SSR treatments became increasingly more noticeable. However, community assemblages between seeding mixtures were found to be less distinct from one another which expresses the dynamics of recently reclaimed grasslands. For example, while intentionally seeded C3 forbs occurred more frequently in G/F and TSF treatments, C3 forbs were a primary driver of the vegetation community for G and SSR treatments. Expression of those short-lived species found on G and SSR treatments in 2019 and the retention of longer lived C3 forb species found in G/F and TSR treatments may have prompted this shift in assemblages between seeding mixtures. Additionally, C4 grasses and C4 forbs (i.e., SATR (Salsola tragus) and BASC (Bassia scoparia); annual invasive species) became prominent drivers of species composition in 2020. The $\mathrm{C} 4$ grasses appear to more readily occupy G/F and TSR treatments, but C4 forbs seemingly occupy all treatments. C4 grass prominence is not wholly uncommon in restored grasslands (Camill et al. 2004), but the broad occurrence of C4 forbs across all treatments may contribute to the increased similarity between seeding mixtures' community assemblages. Early predominance of seeded species, especially the forbs and $\mathrm{C} 4$ grasses, indicates that G/F and TSF treatments are promoting conditions for a desirable plant community, with the exception of KBG. Yet, the interaction between G/F and TSR and G and SSR treatments, along with the overlapping community composition that exists among these different main effects may indicate that these communities are becoming increasingly more similar over time.

One notable trend not observed on any of our treatments was the strong influence of exotic species. This is 
especially notable given previous research efforts attributed uneven surfaces created by ripping/disking/tilling to increased weed production via seed capture (Redente, E.F. \& Hargis 1985). Treatments that experienced TSR (i.e., surface level disturbance) had a greater association with natives in 2019 and 2020. Strong establishment of native species from the seed mixtures and/or seed bank may be inhibiting the initial establishment of exotic species, preventing exotic species to be dominate drivers of species composition. However, chances of invasion by aggressive non-native species can, and often do, increase over time.

Early findings suggest, when used together, TSR and G/F mixtures could aid in improving the growing conditions, especially for native, perennial, C3 grasses and intentionally seeded C3 forbs species. However, our results found that those treatments actively reclaimed with combinations of alternative reclamation practices were not significantly different to standard practices (i.e., the reference site). Thus, early trends indicate that standard practices are providing relatively similar conditions to those created by alternative reclamation practices. It must be noted though that while TSR and G/F were found to have the lowest PR values, average PR values at all depths for these treatments fell between 4.25-6.13 MPa, which is well above the $2 \mathrm{MPa}$ that restrict root penetration (Benjamin et al. 2003). Additionally, the application of ripping occurred only once in this study and settling and dispersion of soil particles due to rain events often result in re-compaction of previously ripped/tilled areas (Busscher et al. 2002). For this reason, it is important that PR readings continue to be taken to determine if the effects of these alternative reclamation practices will persist or change over time.

Variability between reclamation combinations was most notable at the 30 and $40 \mathrm{~cm}$ depth intervals which is most likely the depth where ripping activities, from the $56 \mathrm{~cm}$ ripping shanks, were most impactful for those TSR treatments. Generally, at these depths TSR treatments had the lowest volumetric soil moisture compared to those that received SSR. Decreased soil moisture on TSR treatments at these depths indicates greater infiltration and dispersion of water is occurring likely as a function of the mechanical creation of macropores (Hangen et al. 2002). Comparatively, SSR which experienced no surface-level ripping activities, had greater volumetric soil moisture possibly attributing to the disproportionate amount of micropores that developed from compacted conditions that developed during pre and post mining activities. Given smaller pores tend to hold water more tightly, perhaps the micropores contributed to a greater retention of water. While surface-level manipulations, or the lack of, seems to be the simplest explanation for these trends, variation of volumetric soil moisture between treatments was also associated, to varying degrees, with the seed mixtures. Treatments with combinations of TSR and G/F consistently showed significant differences from SSR and G plus mulch treatments, as with PR and community composition. However, the TSR treatments are still relatively compacted, and without species specific root data it is hard to determine how much the individual species are influencing the soil moisture at the 30 and $40 \mathrm{~cm}$ depth intervals.

\section{Conclusions}

Current traditional best reclamation practices struggle to establish and sustain a native landscape due to challenges often associated with soil compaction and aggressive non-natives. Alleviating soil compaction due to surface mining often times takes place years to decades after reclamation had ceased and/or frequently emphasizes the establishment of woody plant communities. We investigated how combinations of alternative reclamation practices, applied during the process, affected native grassland species composition, and influenced KBG establishment. Generally, our findings indicate when G/F seed mixtures are combined with TSR (plus mulch) intentionally planted native species will be well represented and PR resistance will be lower compared to other combinations of reclamation practices. Those treatments planted to $\mathrm{G}$ and reclaimed with SSR (plus mulch) had higher PR at all depths and were not as strongly associated with planted native species, but these treatments had less KBG cover compared to other reclamation combinations.

These findings provide valuable insight into early stages of ecological recovery for reclaimed grasslands as a function of these alternative reclamation practices. However, it is important to note that PR values for the reference site (i.e., standard practices), at all three depths, were not different from any of the alternative reclamation practices. Yet, ecological recovery of newly reclaimed landscapes takes time, and as time progresses some of the beneficial conditions created by our alternative practices could be enhanced or regress, 
changing the current trajectory. Therefore, continued monitoring of these difference reclamation combinations is important for understanding the effects soil properties have on reclaimed grasslands plant communities to determine if intermittent maintenance is necessary long-term.

\section{Acknowledgements}

Authors thank the North Dakota Industrial Commission-Lignite Research Council for funding (FY16-LXXX204) and to Jay Volk and Greg Petrick at BNI for project assistance.

\section{References}

Ashby, W. C. (1997). Soil ripping and herbicides enhance tree and shrub restoration on stripmines. Restoration Ecology, 5 (2), 169-177. doi:10.1046/j.1526-100X.1997.09720.x

Bates, D., Machler, M., Bolker, B. M., \& Walker, S. C. (2015). Fitting Linear Mixed-Effects Models Using lme4. Journal of Statistical Software, 67 (1), 1-48. doi:10.18637/jss.v067.i01

Bauman, J. M., Keiffer, C. H., \& McCarthy, B. C. (2014). Growth performance and chestnut blight incidence (Cryphonectria parasitica) of backcrossed chestnut seedlings in surface mine restoration. New Forests, 45 (6), 813-828. doi:10.1007/s11056-014-9439-3

Beckett, C. T. S., Glenn, D., Bradley, K., Guzzomi, A. L., Merritt, D., \& Fourie, A. B. (2017). Compaction conditions greatly affect growth during early plant establishment. Ecological Engineering, 106 , 471-481. doi:10.1016/j.ecoleng.2017.04.053

Benjamin, J. G., Nielsen, D. C., \& Vigil, M. F. (2003). Quantifying effects of soil conditions on plant growth and crop production. Geoderma, 116 (1-2), 137-148. doi:10.1016/s0016-7061(03)00098-3

Bohrer, S. L., Limb, R. F., Daigh, A. L., Volk, J. M., \& Wick, A. F. (2017). Fine and Coarse-Scale Patterns of Vegetation Diversity on Reclaimed Surface Mine-land Over a 40-Year Chronosequence.Environmental Management, 59 (3), 431-439. doi:10.1007/s00267-016-0795-y

Bohrer, S. L., Limb, R. F., Daigh, A. L. M., \& Volk, J. M. (2017). BELOWGROUND ATTRIBUTES ON RECLAIMED SURFACE MINE LANDS OVER A 40-YEAR CHRONOSEQUENCE. Land Degradation 83 Development, 28 (7), 2290-2297. doi:10.1002/ldr.2758

Busscher, W. J., Bauer, P. J., \& Frederick, J. R. (2002). Recompaction of a coastal loamy sand after deep tillage as a function of subsequent cumulative rainfall. Soil \&3 Tillage Research, 68 (1), 49-57. doi:10.1016/s01671987(02)00083-1

Camill, P., McKone, M. J., Sturges, S. T., Severud, W. J., Ellis, E., Limmer, J., . . . Trout, A. (2004). Community- and ecosystem-level changes in a species-rich tallgrass prairie restoration.Ecological Applications, 14 (6), 1680-1694. doi:10.1890/03-5273

Fields-Johnson, C. W., Burger, J. A., Evans, D. M., \& Zipper, C. E. (2014). Ripping Improves Tree Survival and Growth on Unused Reclaimed Mined Lands. Environmental Management, 53 (6), 1059-1065. doi:10.1007/s00267-014-0261-7

Foster, B. L., \& Tilman, D. (2000). Dynamic and static views of succession: Testing the descriptive power of the chronosequence approach. Plant Ecology, 146 (1), 1-10. doi:10.1023/a:1009895103017

Fox, J. and S. Weisberg (2019) An $\{\mathrm{R}\}$ Companion to Applied Regression, Third Edition. Thousand Oaks CA: Sage. URL:https://socialsciences.mcmaster.ca/jfox/Books/Companion/

Getahun, G. T., Katterer, T., Munkholm, L. J., Parvage, M. M., Keller, T., Rychel, K., \& Kirchmann, H. (2018). Short-term effects of loosening and incorporation of straw slurry into the upper subsoil on soil physical properties and crop yield. Soil $\mathscr{E}$ Tillage Research, 184 ,62-67. doi:10.1016/j.still.2018.06.007

Hamza, M. A., \& Anderson, W. K. (2005). Soil compaction in cropping systems - A review of the nature, causes and possible solutions. Soil \&3 Tillage Research, 82 (2), 121-145. doi:10.1016/j.still.2004.08.009 
Hangen, E., Buczko, U., Bens, O., Brunotte, J., \& Huttl, R. F. (2002). Infiltration patterns into two soils under conventional and conservation tillage: influence of the spatial distribution of plant root structures and soil animal activity. Soil \& Tillage Research, 63 (3-4), 181-186. doi:10.1016/s0167-1987(01)00234-3

Holl, K. D. (2002). Long-term vegetation recovery on reclaimed coal surface mines in the eastern USA. Journal of Applied Ecology, 39 (6), 960-970. doi:10.1046/j.1365-2664.2002.00767.x

Jabro, J. D., Iversen, W. M., Evans, R. G., Allen, B. L., \& Stevens, W. B. (2014). Repeated Freeze-Thaw Cycle Effects on Soil Compaction in a Clay Loam in Northeastern Montana. Soil Science Society of America Journal, 78 (3), 737-744. doi:10.2136/sssaj2013.07.0280

Kulli, B., Gysi, M., \& Fluhler, H. (2003). Visualizing soil compaction based on flow pattern analysis. Soil $\mathscr{E}$ Tillage Research, 70 (1), 29-40. doi:10.1016/s0167-1987(02)00121-6

Lenth, R. V. (2016). Least-Squares Means: The R Package lsmeans. Journal of Statistical Software, 69 (1), 1-33. doi:10.18637/jss.v069.i01

McDonald, R. I., Fargione, J., Kiesecker, J., Miller, W. M., \& Powell, J. (2009). Energy Sprawl or Energy Efficiency: Climate Policy Impacts on Natural Habitat for the United States of America. Plos One, 4 (8). doi:10.1371/journal.pone.0006802

McSweeney, K., \& Jansen, I. J. (1984). SOIL STRUCTURE AND ASSOCIATED ROOTING BEHAVIOR IN MINESOILS. Soil Science Society of America Journal, 48 (3), 607-612. doi:10.2136/sssaj1984.03615995004800030028x

Mendiburu, Felipe de (2020) agricolae: Statistical Procedures for Agricultural Research. R

package version 1.3-3. https://CRAN.R-project.org/package=agricolae

Middleton, E. L., Bever, J. D., \& Schultz, P. A. (2010). The Effect of Restoration Methods on the Quality of the Restoration and Resistance to Invasion by Exotics. Restoration Ecology, 18 (2), 181-187. doi:10.1111/j.1526-100X.2008.00501.x

NDAWN North Dakota Agricultural Weather Network (2021) North Dakota State University (http://ndawn.ndsu.nodak.edu) Accessed date 01/2021

Oksanen, J.F., F. G. Blanchet, M. Friendly, R. Kindt, P. Legendre, D. McGlinn, P. R. Minchin, R. B. O'Hara, G. L. Simpson, P. Solymos, M.H.H. Stevens, E. Szoecs, and H. Wagner (2019). vegan: Community Ecology Package. R package version 2.5-6. https://CRAN.R-project.org/package=vegan

Otto, C. R. V., Roth, C. L., Carlson, B. L., \& Smart, M. D. (2016). Land-use change reduces habitat suitability for supporting managed honey bee colonies in the Northern Great Plains. Proceedings of the National Academy of Sciences of the United States of America, 113 (37), 10430-10435. doi:10.1073/pnas.1603481113

Pauletto, E. A., Stumpf, L., Pinto, L. F. S., da Silva, T. S., Ambus, J. V., Garcia, G. F., . . Albert, R. P. (2016). Reclamation of a Degraded Coal-Mining Area with Perennial Cover Crops. Revista Brasileira De Ciencia Do Solo, 40 .

Pauletto, E. A., Stumpf, L., Pinto, L. F. S., Silva, T. S. d., Ambus, J. V., Garcia, G. F., . . Albert, R. P. (2016). Reclamation of a Degraded Coal-Mining Area with Perennial Cover Crops. Revista Brasileira De Ciencia Do Solo, 40 (0), e0150482. doi:10.1590/18069657rbcs20150482

Preston, T. M., \& Kim, K. (2016). Land cover changes associated with recent energy development in the Williston Basin; Northern Great Plains, USA. Science of the Total Environment, 566 , 1511-1518. doi:10.1016/j.scitotenv.2016.06.038

Redente, E. F., \& Hargis, N. E. (1985). AN EVALUATION OF SOIL THICKNESS AND MANIPULATION OF SOIL AND SPOIL FOR RECLAIMING MINED LAND IN NORTHWEST COLORADO. Reclamation \& Revegetation Research, 4 (1), 17-29. 
Redente, E. F., McLendon, T., \& Agnew, W. (1997). Influence of topsoil depth on plant community dynamics of a seeded site in northwest Colorado. Arid Soil Research and Rehabilitation, 11 (2), 139-149. doi:10.1080/15324989709381467

Schneider, F., Don, A., Hennings, I., Schmittmann, O., \& Seidel, S. J. (2017). The effect of deep tillage on crop yield - What do we really know? Soil \& Tillage Research, 174 , 193-204. doi:10.1016/j.still.2017.07.005

Shaffer, J. A., \& Buhl, D. A. (2016). Effects of wind-energy facilities on breeding grassland bird distributions. Conservation Biology, 30 (1), 59-71. doi:10.1111/cobi.12569

Sheoran, V., Sheoran, A. S., \& Poonia, P. (2010) SOIL RECLAMATION OF ABANDONED MINE LAND BY REVEGETATION: A REVIEW. International Journal of Soil, Sediment and Water : 3(2) , 1-20

Sluis, W. J. (2002). Patterns of species richness and composition in re-created grassland. Restoration Ecology, 10 (4), 677-684. doi:10.1046/j.1526-100X.2002.01048.x

SMCRA (1977) Surface Mining Control and Reclamaiton Act Office of Surface Mining Reclamation and Enforcement (SMRE)-Laws, Regulations, and Guidance. https://www.osmre.gov/lrg.shtm. Accessed $09 / 19 / 2018$.

Stoessel, F., Sonderegger, T., Bayer, P., \& Hellweg, S. (2018). Assessing the environmental impacts of soil compaction in Life Cycle Assessment. Science of the Total Environment, 630 , 913-921. doi:10.1016/j.scitotenv.2018.02.222

Stumpf, L., Pauletto, E. A., \& Pinto, L. F. S. (2016). Soil aggregation and root growth of perennial grasses in a constructed clay minesoil.Soil \& Tillage Research, 161 , 71-78. doi:10.1016/j.still.2016.03.005

Tardieu, F. (1994). GROWTH AND FUNCTIONING OF ROOTS AND OF ROOT SYSTEMS SUBJECTED TO SOIL COMPACTION - TOWARDS A SYSTEM WITH MULTIPLE SIGNALING.Soil \& Tillage Research, 30 (2-4), 217-243. doi:10.1016/0167-1987(94)90006-x

Trainor, A. M., McDonald, R. I., \& Fargione, J. (2016). Energy Sprawl Is the Largest Driver of Land Use Change in United States. Plos One, 11 (9). doi:10.1371/journal.pone.0162269

Unger, P. W., \& Kaspar, T. C. (1994). SOIL COMPACTION AND ROOT-GROWTH - A REVIEW. Agronomy Journal, 86 (5), 759-766. doi:10.2134/agronj1994.00021962008600050004x

USDA-NRCSa (2021a) United States Dept. of Agriculture, Natural Resources Conservation Service Web Soil Survey (http://websoilsurvey.sc.egov.usda.gov/) Soil Survey Statff Accessed 01/2021

USDA-NRCSb (2021b) United States Dept. of Agriculture, Natural Resources Conservation Service The PLANTS Database (http://plants.usda.gov) National Plant Data Team Accessed 02/2021

Zhao, Y. G., Pang, H. C., Wang, J., Huo, L., \& Li, Y. Y. (2014). Effects of straw mulch and buried straw on soil moisture and salinity in relation to sunflower growth and yield. Field Crops Research, 161 , 16-25. doi:10.1016/j.fcr.2014.02.006 


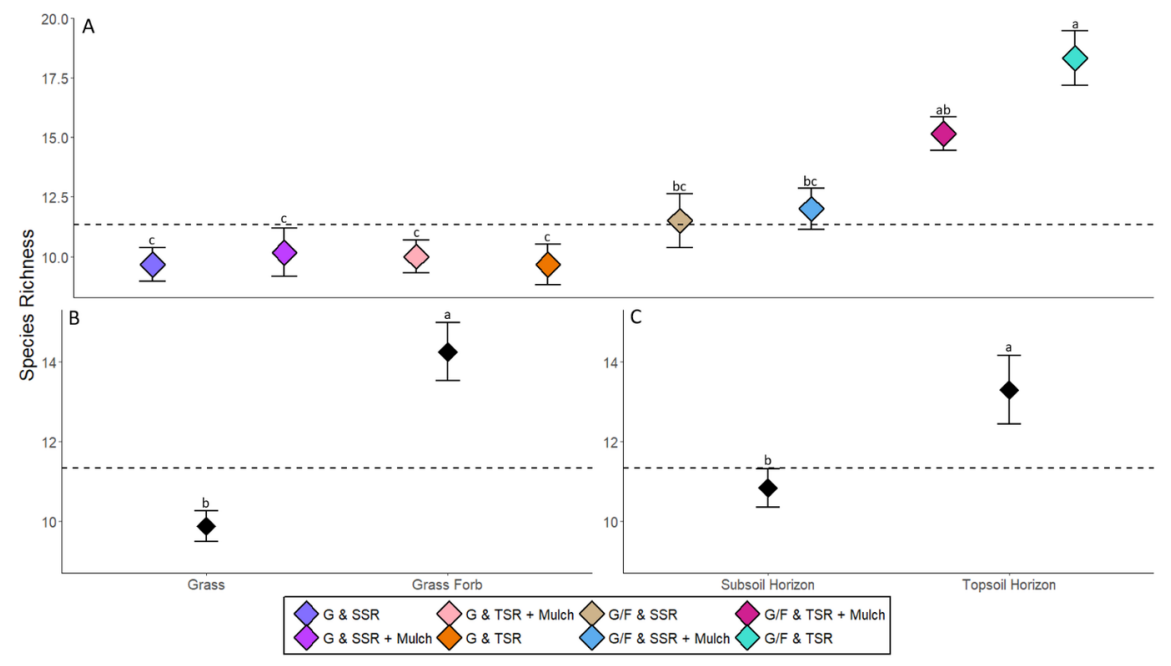

Figure 1. 2019 plant species richness as function of reclamation treatments (A), seeding mixture (B), and ripping technique $(\mathrm{C})$. Bars denote one standard error. Means with same letter are not significantly different $(\mathrm{p}<0.10)$. Dotted line represents mean value of reference site. Data were collected in July 2019 from BNI Coal, LTD, near Center, ND USA.

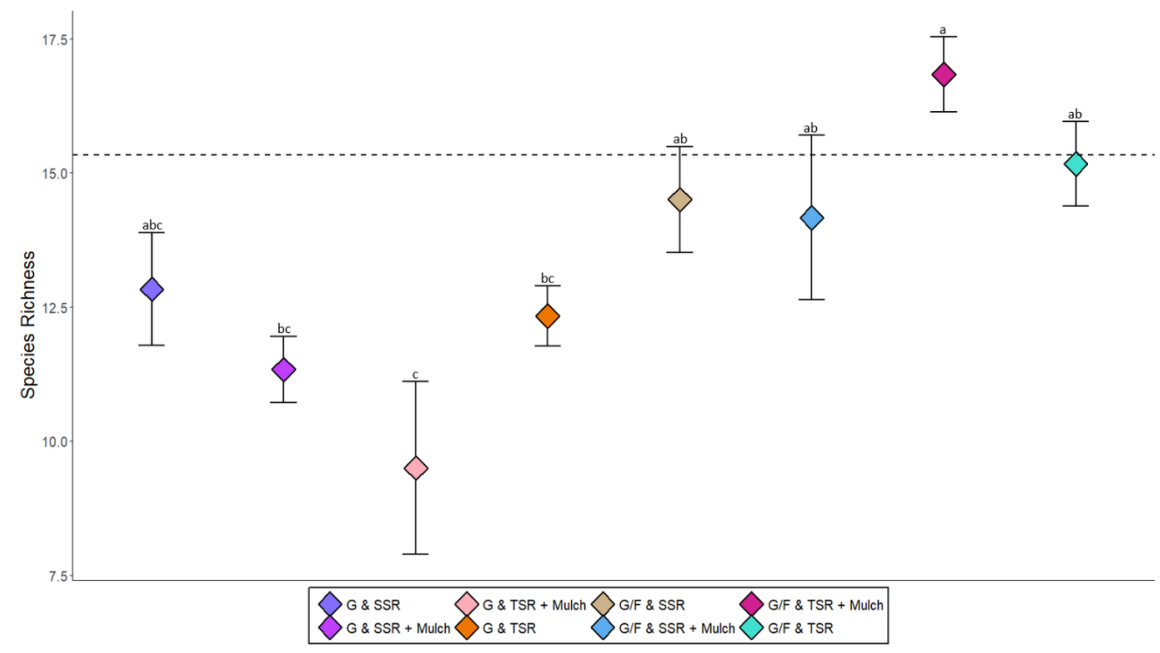

Figure 2. 2020 plant species richness as function of reclamation treatments. Bars denote one standard error. Means with same letter are not significantly different $(\mathrm{p}<0.10)$. Dotted line represents mean value of reference site. Data were collected in July 2020 from BNI Coal, LTD, near Center, ND USA. 


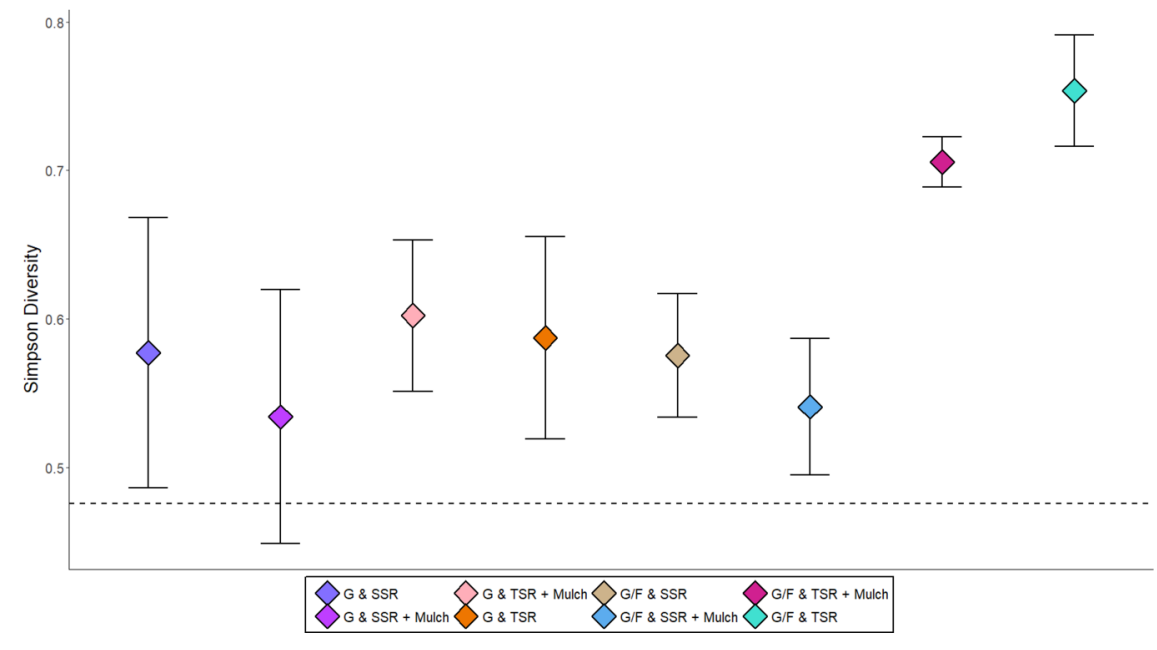

Figure 3. 2019 plant species diversity as function of reclamation treatments. Bars denote one standard error. Dotted line represents mean value of reference site. Data were collected in July 2019 from BNI Coal, LTD, near Center, ND USA.

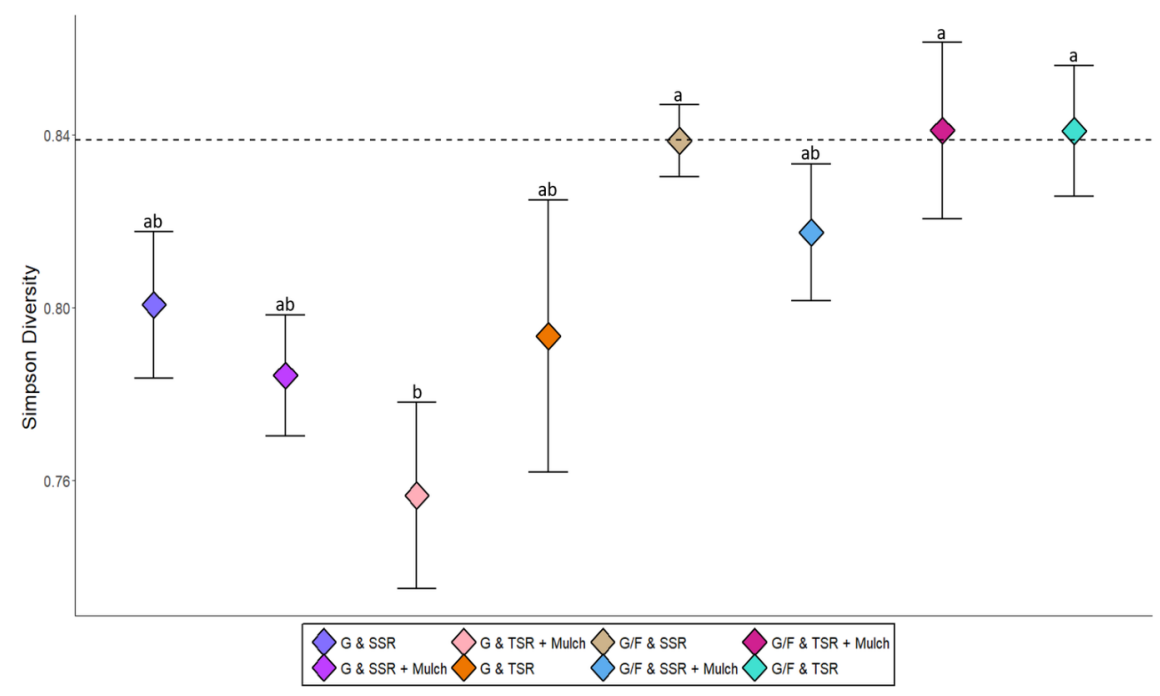

Figure 4. 2020 plant species diversity as function of reclamation treatments. Bars denote one standard error. Means with same letter are not significantly different $(\mathrm{p}<0.10)$. Dotted line represents mean value of reference site. Data were collected in July 2020 from BNI Coal, LTD, near Center, ND USA. 


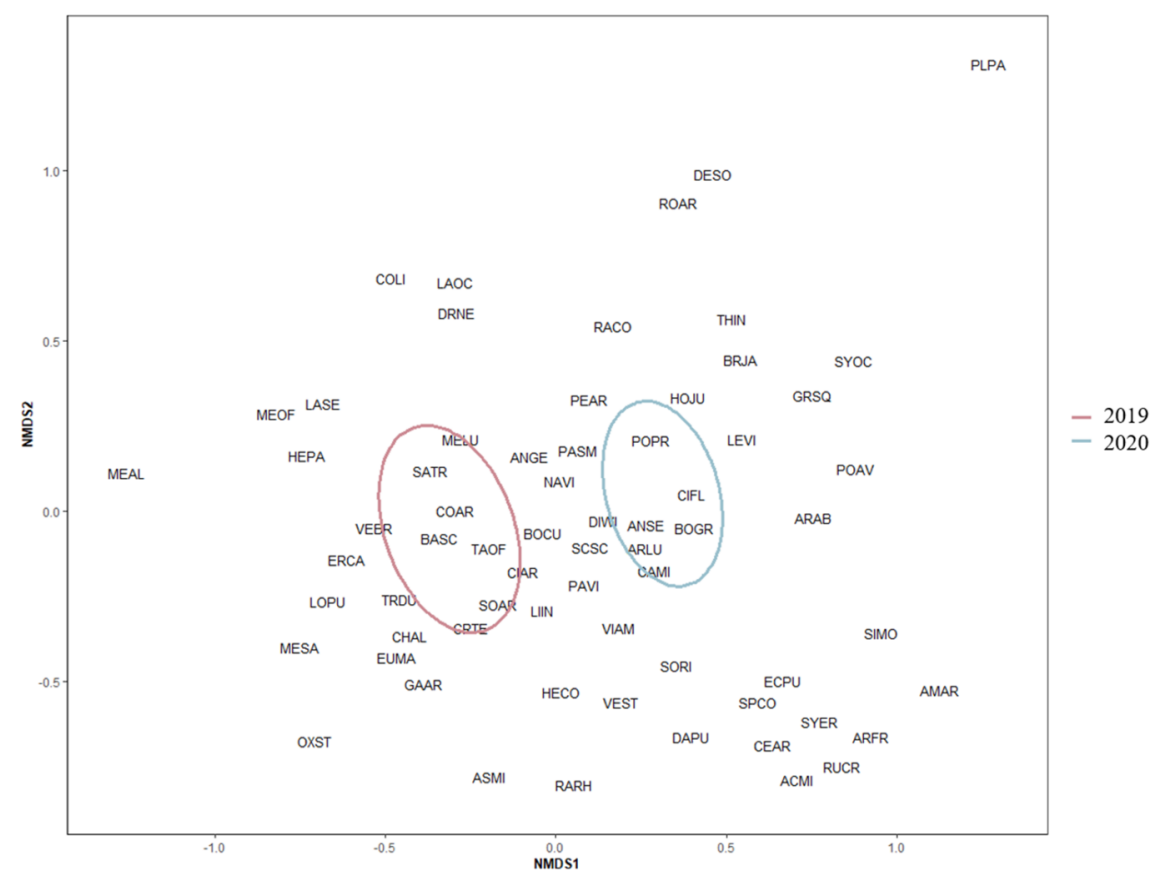

Figure 5. NMDS ordination of plant community composition by year. Species composition of treatments with ellipses representing years; $\mathrm{k}=3$, stress $=0.19$. Data were collected in July 2019 and 2020 from BNI Coal, LTD, near Center, ND USA.

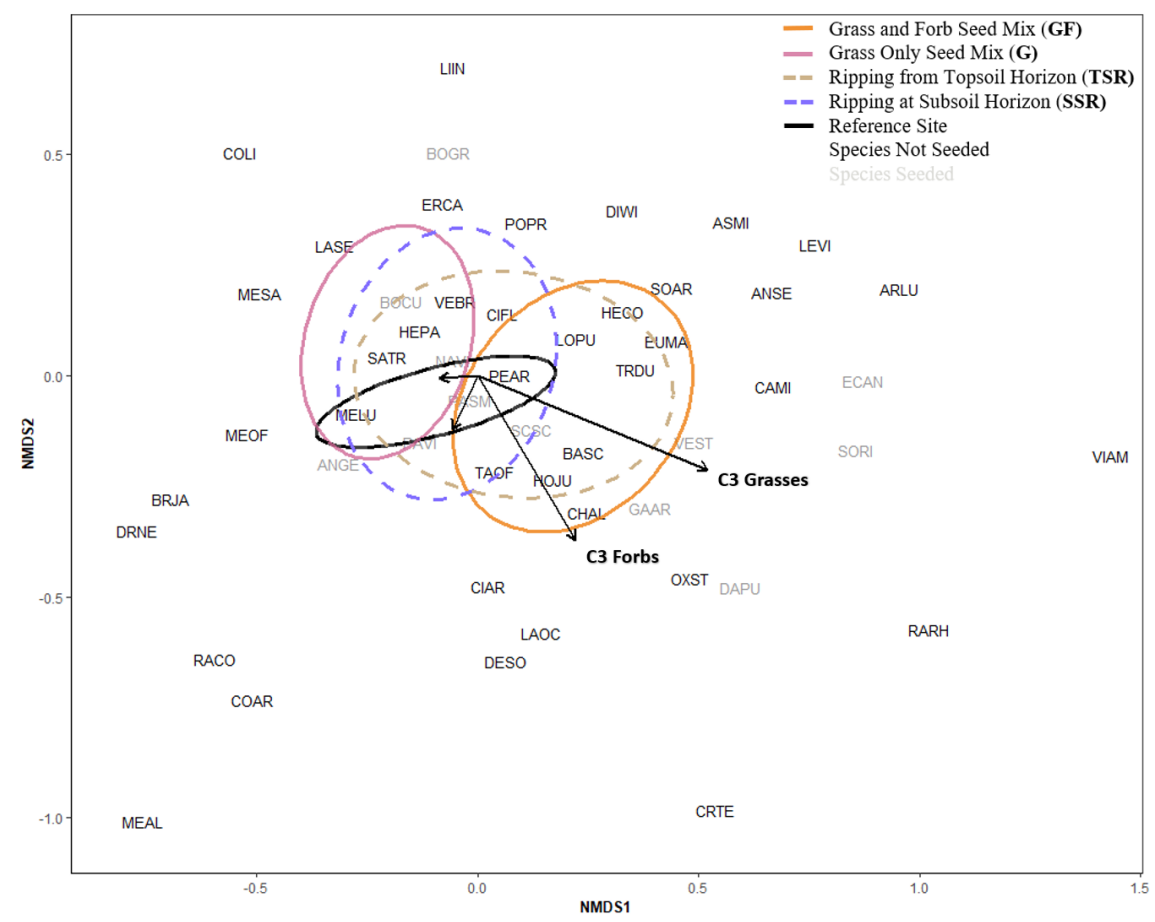

Figure 6. 2019 NMDS ordination of plant community composition. Species composition of 2019 with ellipses representing seeding mixtures (solid lines) and ripping technique (dashed lines); $\mathrm{k}=3$, stress $=0.20$. Vectors 
provide community composition associations given different metabolic/life-forms. Vectors not labelled were not significant. Species code coloration is dictated by whether the species was in the seed bank (i.e., Species Not Seeded; black text) or part of the seed mixes (i.e., Species Seeded; grey text). Data were collected in July 2019 from BNI Coal, LTD, near Center, ND USA.

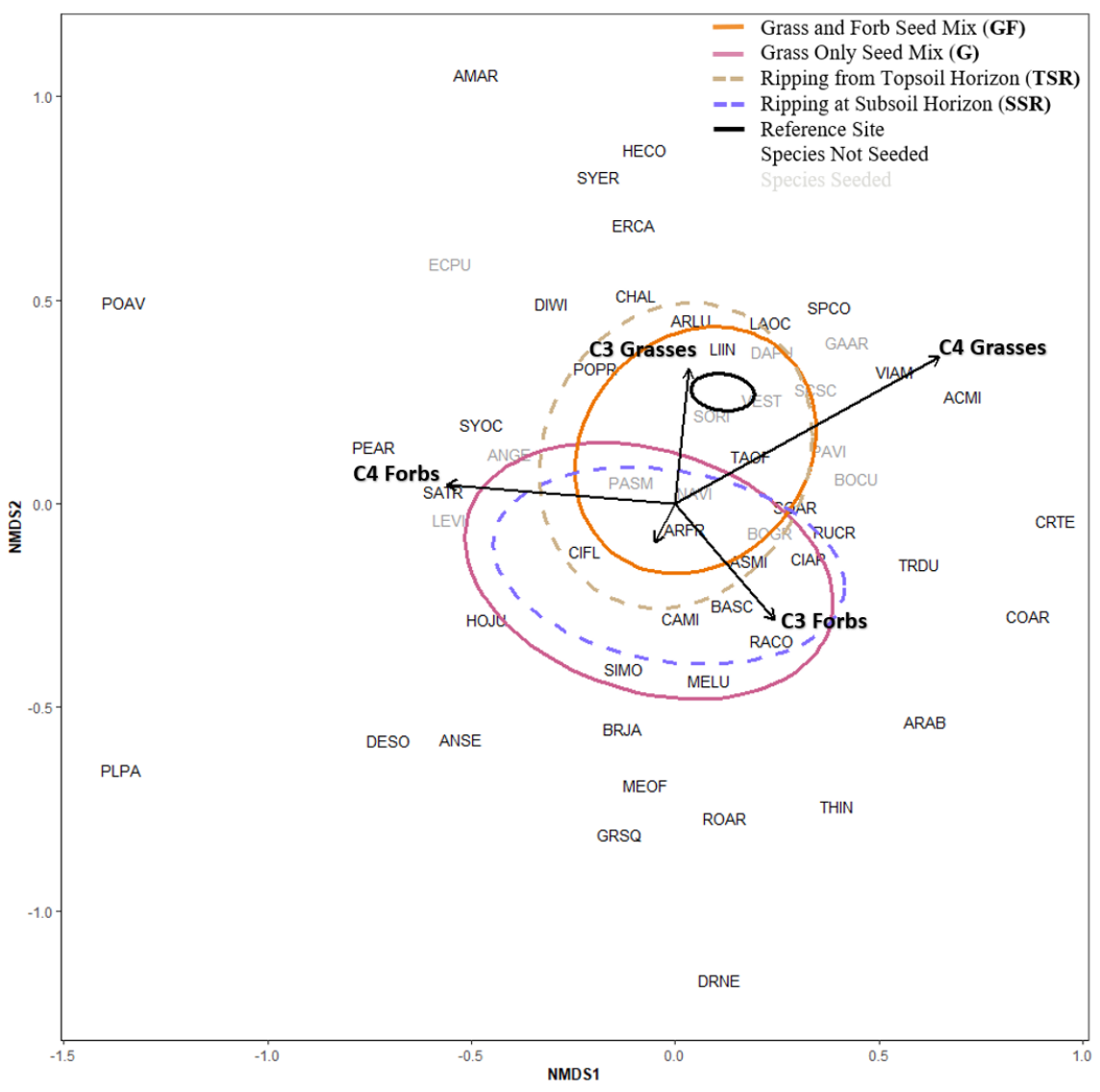

Figure 7. 2020 NMDS ordination of plant community composition. Species composition of 2020 with ellipses representing seeding mixtures (solid lines) and ripping technique (dashed lines); $\mathrm{k}=3$, stress $=0.18$. Vectors provide community composition associations given different metabolic/life-forms. Vectors not labelled were not significant. Species code coloration is dictated by whether the species was in the seed bank (i.e., Species Not Seeded; black text) or part of the seed mixes (i.e., Species Seeded; grey text). Data were collected in July 2020 from BNI Coal, LTD, near Center, ND USA. 


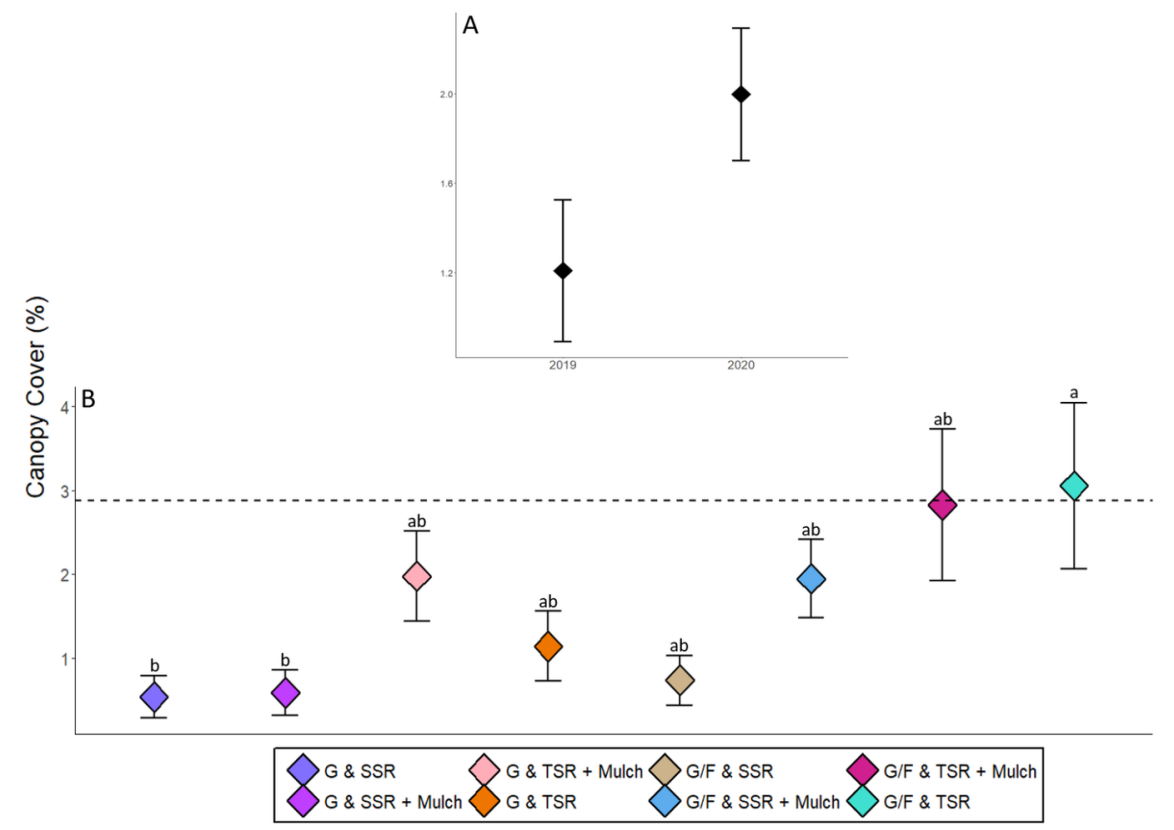

Figure 8. Percent canopy cover of Kentucky bluegrass (Poa pratensis). Percent cover as a function of year (A) and treatment with both years assessed collectively (B) at BNI. Bars denote one standard error. Means with same letter are not significantly different $(\mathrm{p}<0.10)$. Data were collected in July 2019 and 2020 from BNI Coal, LTD, near Center, ND USA.

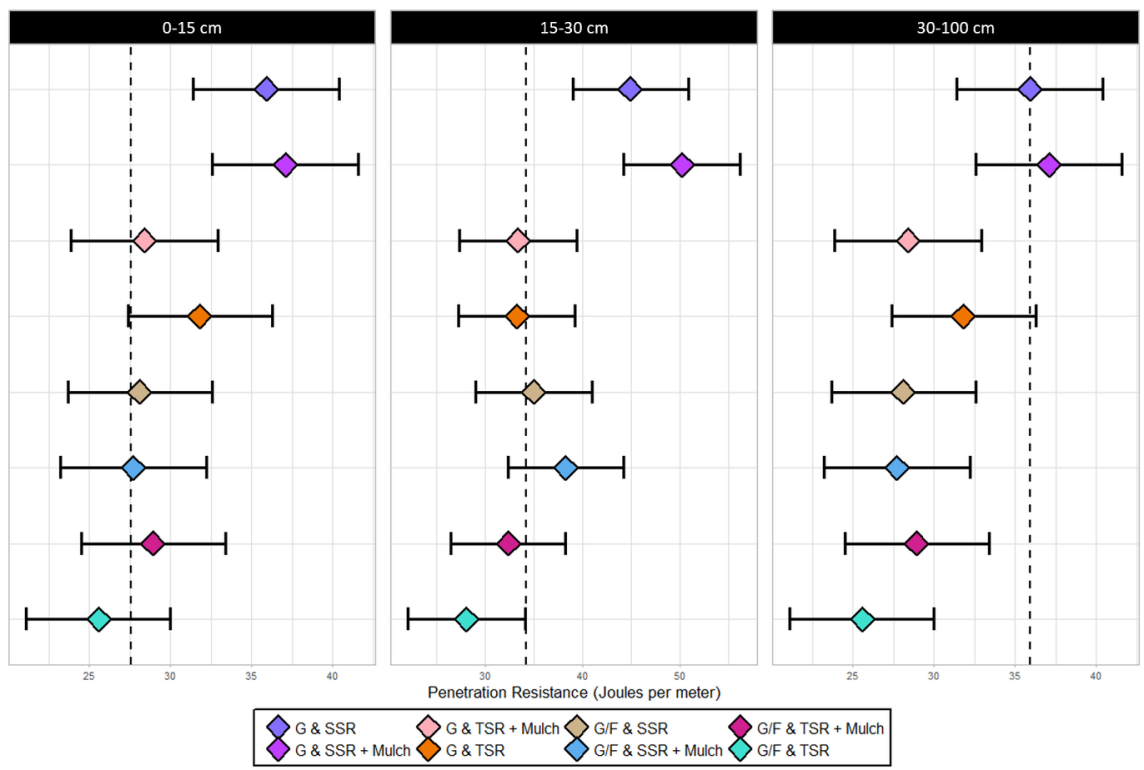

Figure 9. Penetration resistance by depth as a function of reclamation treatments. Three depth bins were 0-15, 15-30, and 30-100 cm. Values are in Joules per meter. Bars denote 90\% confidence intervals. Dotted line represents mean value of reference site. Data were collected in between July and September in 2018 -2020 from BNI Coal, LTD, near Center, ND USA. 


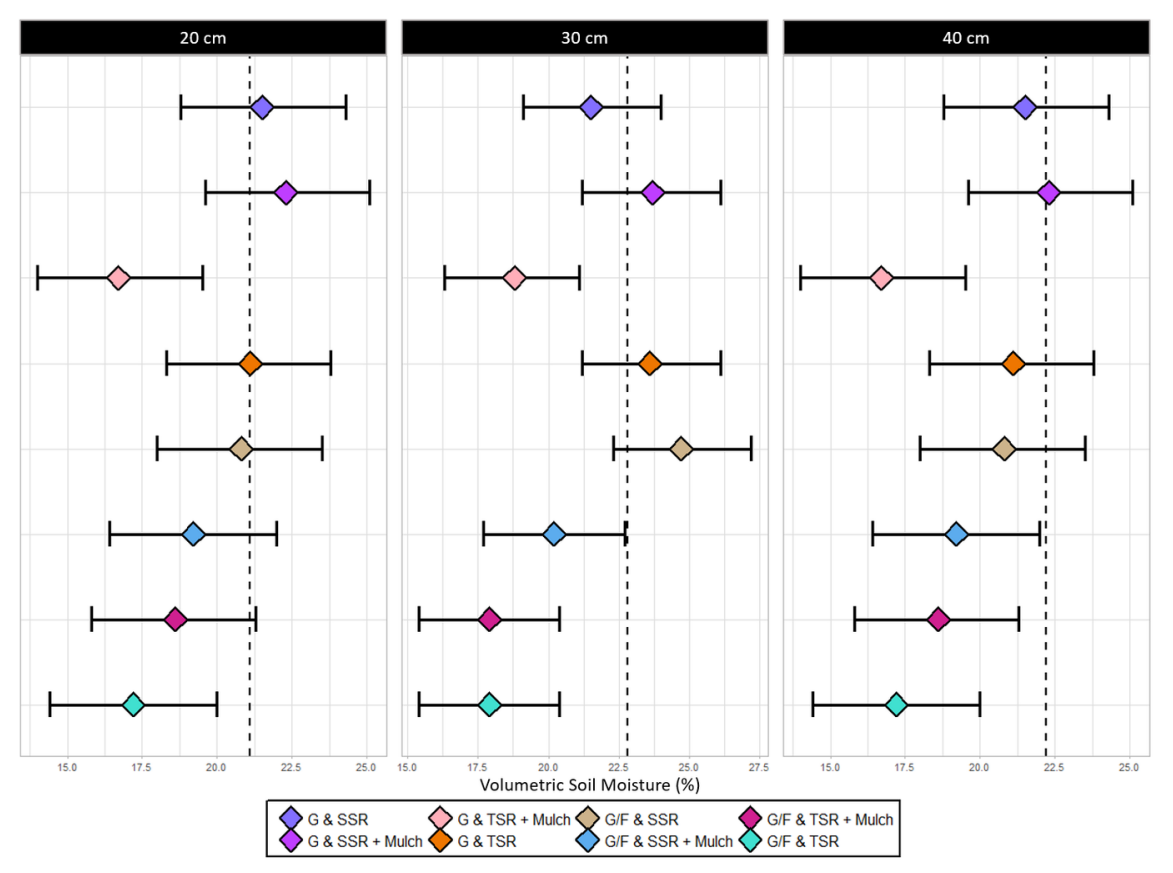

Figure 10. Volumetric soil moisture by depth as a function of reclamation treatments. Three separate depths were 20,30, and $40 \mathrm{~cm}$. Values as percentages. Bars denote $90 \%$ confidence intervals. Dotted line represents mean value of reference site. Data were collected in between July and September in 2018 -2020 from BNI Coal, LTD, near Center, ND USA.

\section{Hosted file}

Table 1.docx available at https://authorea.com/users/461412/articles/557113-mechanical-andbiotic-strategies-for-post-mine-reclaimed-grasslands

\section{Hosted file}

Table 2.docx available at https://authorea.com/users/461412/articles/557113-mechanical-andbiotic-strategies-for-post-mine-reclaimed-grasslands 